\title{
Prevalence and risk factors of low back disorders among waste collection workers: A systematic review
}

\author{
Benedicta O. Asante, Catherine Trask*, Olugbenga Adebayo and Brenna Bath \\ Canadian Centre for Health and Safety in Agriculture, College of Medicine, University of Saskatchewan, \\ Saskatoon, Canada
}

Received 19 October 2017

Accepted 4 November 2018

\begin{abstract}
.
BACKGROUND: Waste management is a growing industry worldwide. Working conditions may entail risk factors for musculoskeletal disorders, and especially low back disorders (LBD).

OBJECTIVE: The purpose of this study was to perform a systematic review on: (i) the prevalence of LBD; and (ii) risk factors for LBD among waste collection workers.

METHOD: A search was conducted in three electronic databases: Ovid Medline, EMBASE, and Global Health ePublications. Data were extracted on study design, sampling strategy, geographical region, LBD prevalence, and risk factors. Data were reported narratively.

RESULTS: Thirteen full-text articles met the study criteria. Using a range of definitions for LBD, the included articles reported a 12-month prevalence of 'LBD' between 16 to $74 \%$, although none of the included studies quantified relationships between risk factors and LBD. None of the studies met all 9 risk of bias criteria. No articles investigated the association of risk factors and LBD, but even in absence this evidence authors of included studies suggested physical risk factors for LBD among waste workers: awkward posture, repetitive motion, and work duration.

CONCLUSION: In light of these risks and future growth in this industry, the lack of high quality studies and investigation of risk factors highlight the need for more research in this sector which will support future LBD prevention efforts.
\end{abstract}

Keywords: Back pain, scavengers, waste pickers, recycling

\section{Background}

Low back disorders (LBD) are an umbrella description encompassing a multitude of clinical and

\footnotetext{
*Address for correspondence: Catherine Trask, PhD. Canada Research Chair in Ergonomics and Musculoskeletal Health, Associate Professor, Canadian Centre for Health and Safety in Agriculture (CCHSA), University of Saskatchewan, 104 Clinic Place, PO Box 23. Saskatoon, Saskatchewan, S7N 2Z4, Canada. Tel.: +1 306966 5544; E-mail: cmtrask@ gmail.com.
}

etiologic entities without a standardized case definition [1]. Up to $95 \%$ of back pain is considered 'non-specific' without specific detectable anatomical pathologies [2]. LBD are a common global health problem, with a lifetime prevalence over $80 \%$ among workers from any occupation [3-5]. Back disorders have a tremendous economic impact. Among the broad list of 290 diseases and conditions included in the Global Burden of Diseases Study, low back pain is the leading cause of years lived with disability [6] and 
the musculoskeletal disorder which most frequently results in disability [5].

LBD are also reported to be a common musculoskeletal disorder specifically in the waste management sector; authors have hypothesized that this is related to the physical and potentially high risk nature of their work [7]. Waste management involves the collection, transportation, sorting, disposal, and recycling of unwanted materials $[8,9]$ such as plastics, paper, cans, and cardboard amongst others. This process is important for the health of the public as well as aesthetic and environmental reasons [9]. Ineffective management of waste increases odours and degrades the quality of the human surroundings and, in the long run, affects the suitability of the ecosystem to human health.

Manual waste collection is the most common form of gathering waste globally and has been found to be among the occupations with highest risk for injury [10]. Workers who manually manage waste face a unique set of hazards as a result of their daily exposure to work-related hazards [10].These workers, known as waste collection workers (WCW), 'waste pickers', 'recycling workers', 'municipal solid workers', 'solid waste workers' collect materials that have been discarded as waste and help return them into the usable resources by sorting, cleaning, and altering the physical shape to facilitate transport or combine materials in order to make commercially viable products [11]. As in several industries, the activities of these workers in managing waste can be both formal or informal [8]. Formal work is "working for one company and having some type of working agreement, set pay and/or benefits, a stable location, regular hours and some type of payroll taxes and social security contribution" [12] while an informal work situation means "the person doing the work has little or no job security, doesn't have a contract, and might not have the same employer for more than a few weeks or months" [12]. Waste collection work can vary substantially between 'formal' unionized garbage truck attendants and 'informal' scavengers collecting recyclable items form a landfill.

Waste collection workers' activities are significant to the recycling sector, which are regarded as sustainable within the waste management hierarchy [13]. Recycling is an avenue for identifying and retrieving waste as a "resource", and likewise managing the environment as a whole [13]. Scavenging, an example of informal sector waste management, promotes social equity by providing a source of income to those who engage in it to sustain their livelihoods
[14]. Scavengers habitually have decreased access and safety in the health system and are disadvantaged with regards to inequitable health outcomes, which are perpetuated with this line of work. In the process of waste scavenging and sorting, workers may be exposed to awkward positions, repetitive movement, long duration of standing, and vibration from machinery $[7,11,15]$. Workforce exposure estimates can be difficult to calculate due to a high degree of transience and a lack of record-keeping in the informal sector. The International Labour Organization does not have a standard classification of occupations code for waste collectors [16]. Brazil is the only country that gathers data on informal waste collectors (229,000 nationally); however, according to a 2013 study the global workforce in the informal recycling sector is estimated to number in the millions [17]. The World Bank estimated in 2014 that "Solid waste management - formal and informal - represents $1 \%$ to $5 \%$ of all urban employment" [18]. Solid waste generation is increasing with global population growth and economic development $[19,20]$, making this a growing labour sector and an increasingly important occupational health issue.

Waste collection is a growing industrial sector that appears to expose workers to many risk factors for LBD. Hence, there is a need for a review of published scientific literature on LBD related to this understudied group, and identification of hazards they are exposed to while they carry out their daily work. The aim of this systematic review is to summarize evidence on: 1) the prevalence of low back disorders among waste workers; and 2) risk factors for low back disorders among waste workers.

\section{Methods}

This review has focused on two primary research questions: 1) "What is the prevalence of LBD among waste workers"?; and 2) "What are the risk factors for LBD among waste workers"? We used the PICO (i.e. population, intervention, condition, outcome) framework to guide our search. The 'population' of interest was waste collection workers in any global geographical region. When assessing risk factors, the 'intervention' was considered to be exposure to waste collection work, with the comparison group being non-waste collection occupations, or occupations with low exposure to waste collection tasks. The 'condition' or 'outcome' of interest was LBD. All study designs meeting these criteria were considered, 
as long as they were peer-reviewed journal articles and published in English language with no limitations on year of publication.

\subsection{Search strategy}

A search was conducted in three main electronic published databases from inception: Ovid Medline (1946 to 2015), EMBASE (1974 to 2015), and Global Health ePublications (1973 to 2015). The main search terms included conceptual groups of synonyms for "low back disorders" as applied in previous reviews [21], and "waste collection workers" (a full list of search terms is shown in supplemental materials). After the initial search was conducted, the reference lists of included articles were also searched for relevant articles.

Inclusion Criteria: The review included articles published in English language, all study designs, and with subjects age 18 years and older. Eligible articles were peer-reviewed journal articles that reported LBD with any prevalence period and/or risk factors for LBD.

Exclusion Criteria: Non-English language and other non-primary research articles in journals were not included.

\subsection{Screening}

Two reviewers (BA, OA) independently screened the articles generated from the three electronic databases. The two reviewers screened the articles at the title, abstract, and full-text stages. In all the three stages of screening, discrepancies were discussed and resolved by consensus. Continued discordances were resolved with a third reviewer $(\mathrm{CT})$.

\subsection{Data extraction}

Data extraction captured information to address the primary research questions. Extracted information included: author's name and date of publication; sample size; sampling strategy; socio-demographics of the sample; the study design; geographical region; response rate; definition of LBD; LBD prevalence; exposure definition/levels; statistical techniques; and findings of inferential tests on the association between exposure to risk factors and LBD.

The risk of bias of included studies was assessed based on a criteria list recommended by Hoy et al. [22] (See Table 3). Each study was assessed individually and was scored "Yes" if it met a specific criteria

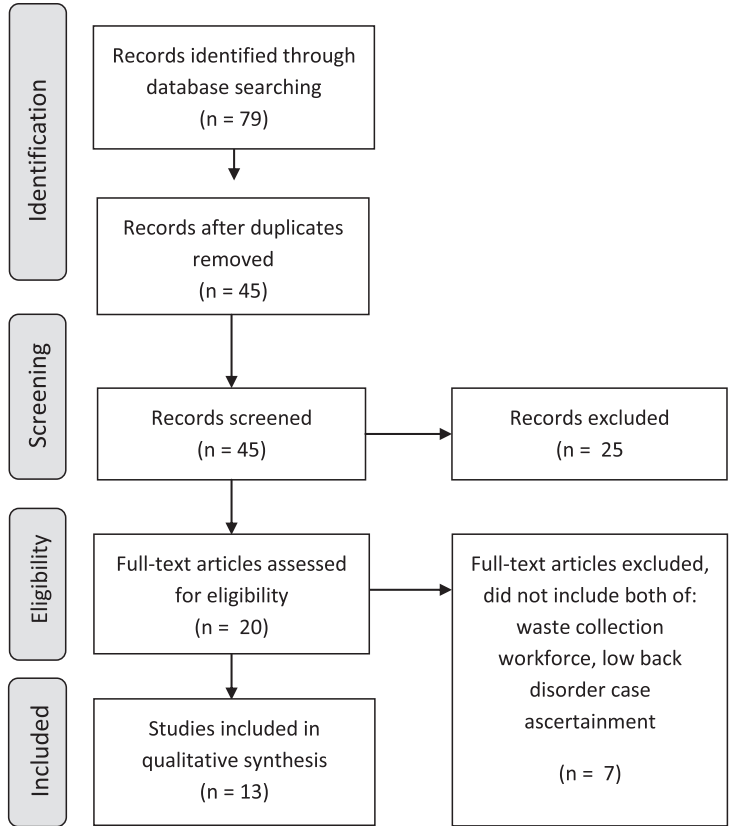

Fig. 1. PRISMA diagram outlining search and screening results for the literature review of low back disorder among waste collection workers.

and "No" if there was no satisfactory information. Two independent reviewers (BA \& OA) extracted the relevant data. Where the results were inconsistent, the two reviewers discussed and consulted a third reviewer $(\mathrm{CT})$ to arrive at consensus.

\section{Results}

\subsection{Search results}

The search generated 79 articles; Ovid Medline (19 articles), EMBASE (55 articles), and Global Health e-publications (5 articles). There were 34 duplicate articles, which left a total of 45 unique for screening; after screening 13 articles were included in this systematic review. Figure 1 shows the results of the screening process.

\subsection{Characteristics of the included articles}

The articles included in the review mostly used descriptive cross-sectional study design (Table 1). These articles had varied sample sizes, ranging from 30 to 900 participants. Five out of the 13 studies were conducted in developed countries [13,23-26] and 8 in developing nations $[10,12,14,15,27-30]$. A higher 


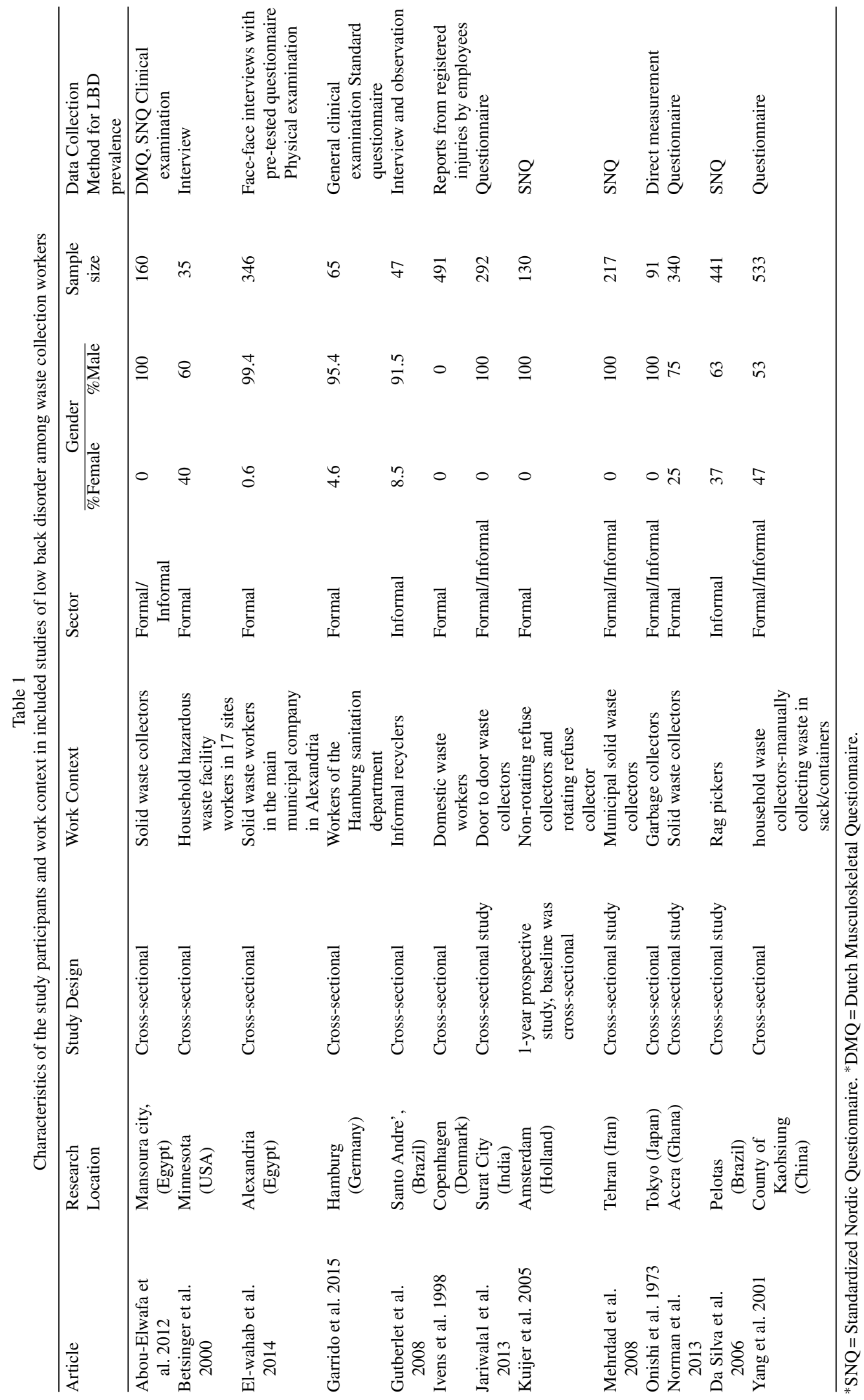


percentage of the articles (54\%) included both male and female study participants [12-14, 23, 27, 29, 30], while $38 \%$ of the articles included only male participants $[10,15,26,28,31]$. One of the articles did not state the sex of its study sample [24]. In terms of work context, two of these studies were conducted among informal workers [12, 14]; six among formal $[13,23-25,27,29]$ and five of the studies used both formal and informal worker participants $[10,15,26$, $28,30]$.

\subsection{LBD case definitions}

Different definitions for LBD were used in the studies, including descriptions as ergonomic/occupational injury, musculoskeletal symptoms, or back complaints. Prevalence was estimated over a 12-month period in the included studies. Of the 13 articles, 8 used standardized survey instruments to define LBD cases. Four of the articles used clinical reports, physical/clinical examinations, or interviews to collect data on LBD. Table 1 gives a summary of the included articles.

\subsection{LBD prevalence among waste workers}

Table 2 presents the prevalence of LBD among waste workers extracted from the 13 included studies. The prevalence from these articles ranged from $16 \%$ to $74 \%$ for a 12 -month period. One article reported a lifetime prevalence ranging from $85 \%$ to $90 \%$ [10]. Twelve-month prevalence was based on identified symptom occurrence in the 12 months prior to the study, while "lifetime prevalence" was estimated as the proportion of respondents who had ever experienced LBD.

\subsection{Risk factors for $L B D$}

None of the included articles specifically examined the association between risk factors and LBD quantitatively. All mentions of risk factors for LBD in this workforce were hypotheses without inferential tests.

\subsection{Study quality: Risk of bias}

The majority of the studies used questionnaires to collect data. Overall, none of these articles met all 9 risk of bias criteria. Fewer articles met the criteria relating to whether their sample represented the true
Table 2

Low back disorder prevalence among waste workers reported in included studies

\begin{tabular}{lcc}
\hline Article & $\begin{array}{c}\text { 12-month } \\
\text { Prevalence }\end{array}$ & $\begin{array}{c}\text { Lifetime } \\
\text { Prevalence }\end{array}$ \\
\hline Betsinger et al. 2000 & $16.0 \%$ & - \\
Ivens et al. 1998 & $17.0 \%$ & - \\
El-wahab et al. 2014 & $17.3 \%$ & - \\
Abou-Elwafa et al. 2012 & $22.5 \%$ & - \\
Onishi et al. 1973 & $32.0 \%$ & - \\
Jariwala et al. 2013 & $38.0 \%$ & - \\
Yang et al. 2001 & $42.0 \%$ & - \\
Kuijer et al. 2005 & $45.0 \%$ & - \\
Mehrdad et al. 2008 & $45.6 \%$ & 85.0 to $90.0 \%$ \\
Da Silva et al. 2006 & $49.2 \%$ & - \\
Gutberlet et al. 2008 & $56.0 \%$ & - \\
Garrido et al. 2015 & $67.2 \%$ & - \\
Norman et al. 2013 & $73.5 \%$ & - \\
\hline
\end{tabular}

Note: $-=$ Not assessed in the article.

population, was selected randomly, had minimal nonresponse bias, clear and acceptable definition, and demonstrated validity of study instrument. Typically, articles scored "No" due to insufficient information reported. This analysis of study risk of bias concluded that the 13 articles included in this systematic review had low to moderate overall quality and thus, "additional studies are likely to change the confidence in estimation" [22].

\section{Discussion}

This study reviewed 13 articles which focused on prevalence of LBD among waste workers. The studies included in this review indicated a wide range of prevalence rates for 12-month LBD (32\% to $74 \%$ ), depending on the LBD definition. Although the review intended to investigate risk factors for LBD, no articles quantifying this relationship were found.

\subsection{LBD prevalence among waste workers}

Low back disorders were defined differently in most of the articles; this may be linked to the variability in reported prevalence rates. All reviewed articles reported 12-month prevalence; prevalence rates varied widely from $16 \%$ [23] to 74\% [29]. The variation in LBD prevalence identified in the present study demonstrates a common issue in LBD research: differences in study design; methodological approach [32]; and LBD case definition. Varying case definitions for 'LBD' are a long-acknowledged issue in LBDs research [33], despite efforts to standardize definitions through expert consensus [34]. There is no 
"gold standard" for LBD case definition [3], demonstrated by the included studies employing a range of methods, including: Standard Nordic Questionnaire (SNQ) [10, 14, 15, 35], Dutch Musculoskeletal Questionnaire (DMQ) [15], clinical injury report, physical examination, observation or interview. For example, recall of LBD symptoms was used in almost all the articles, which may be problematic in estimating the prevalence of LBD [3]. The quality of the methodological strategies used may also contribute to the differences in the reported prevalence. A study by Norman et al. [29] showed that, cross-sectional studies, self-reported data, and bias in recall can under or overestimate the prevalence of LBD among waste workers. Given the variation in data collection methods, tools, and case definitions, it is not unexpected to see a range of prevalence among the 13 studies

Though the included articles focused on a similar occupational group, they did differ in their selection of the study sample, their mode of collecting data, and possibly cultural perceptions of pain across geographic regions. There was no observable relationship between the high and low prevalence studies in terms of risk of bias as studies which had more risk of bias found among the highest and lowest prevalence rates (See Table 3 for risk of bias assessments). Those with the lowest risk of bias tended to be clustered around the central prevalence estimates, ranging from $42 \%$ [30] to $49 \%$ [14]; it seems likely that higher risk of bias leads to less robust estimates of a single central value, though it is also possible that the various populations truly differed in contexts, exposure to risk factors, and thus in prevalence. Work context likewise did not explain the difference in reported prevalence rates: studies that included informal work forces tended to be clustered centrally $[10,12,26$, $28,30]$, and those that included only formal sectors spanned the low [23, 24] and high [13, 29] range of the prevalence estimates.

\subsection{Comparison to other industries}

Although the identified range among these studies was large, the prevalence rates were not substantially different from those reported in other potentially high-risk occupational groups. The prevalence of LBD reported among textile [36], health care workers [37] and office workers [38] are typically 35\% to $55 \%$, within the ranges demonstrated by the 13 articles under review. Ghaffari et al. [39] concluded that the 12-month prevalence for self-reported LBD among Iranian industrial workers was $21 \%$. A cross- sectional study conducted among textile workers by Paudyal et al. [36] showed a 1 month period prevalence of LBP at $35 \%(n=324)$, being higher in females than males $(45 \%$ versus $28 \% ; P<0.001)$. The high handling demands of the health care sector may also provide a similar set of risk factors. Dajah et al. [37] showed a 12-month prevalence of work-related LBD to be $53.2 \%$ among 300 nursing staff, as assessed using Standardized Nordic Questionnaire (LBD was assessed on recall period, episode duration and location of painful area). A study conducted among 74 staff in a rural hospital indicated a 12-month prevalence of LBD 69\% among nurses, 55\% among administrative staff, and $20 \%$ among cleaners [38]. Construction of questionnaire items and individual cultural perceptions in reporting pain could account for some of the regional differences [40]. Comparing the 12-month prevalence reported among Iranian industrial workers $(21 \%)$ [39] to the 12-month prevalence among waste workers in Iran (45.6\%) [10], suggests there an increased risk of LBD among waste workers. How study participants culturally perceive and relate to pain could have resulted in the difference in pain reporting [41].

\subsection{Risk factors for $L B D$}

Although there were no quantified assessments of risk factors for LBD among WCW, several authors hypothesized in their discussions about risk factors which may potentially be contributing to LBD in waste workers: repetitive motion [14, 23, 24]; lifting [7, 23, 29]; force [24]; twisting [29]; short cycle (high repetition) $[29,31]$, manual handling $[29,30]$, work duration [13, 30, 35] smoking [30], physical work load [7, 35], vibration [35] and awkward posture during work [13, 23, 35]. Risk factors are considered to be modifiable or non-modifiable variables associated with an increased risk of disease or health condition [3]. Identified risk factors of LBD would enhance attempts to implement preventive measures [35]. Prior research has focused on age, gender, and lifestyle factors such as smoking as well as physical activity as risk factors for musculoskeletal disorders in general [42]. Others have focused on a range of biopsychosocial factors associated with LBD [43]. Malchaire et al indicated that repetitiveness and posture are considered to be biomechanical risk factors for LBD [42]. Repetitive motion [14, 23, 24], lifting [7, 23, 29] force [24], twisting [29], short cycle (high repetition) [29, 31], manual handling [29, 30], 


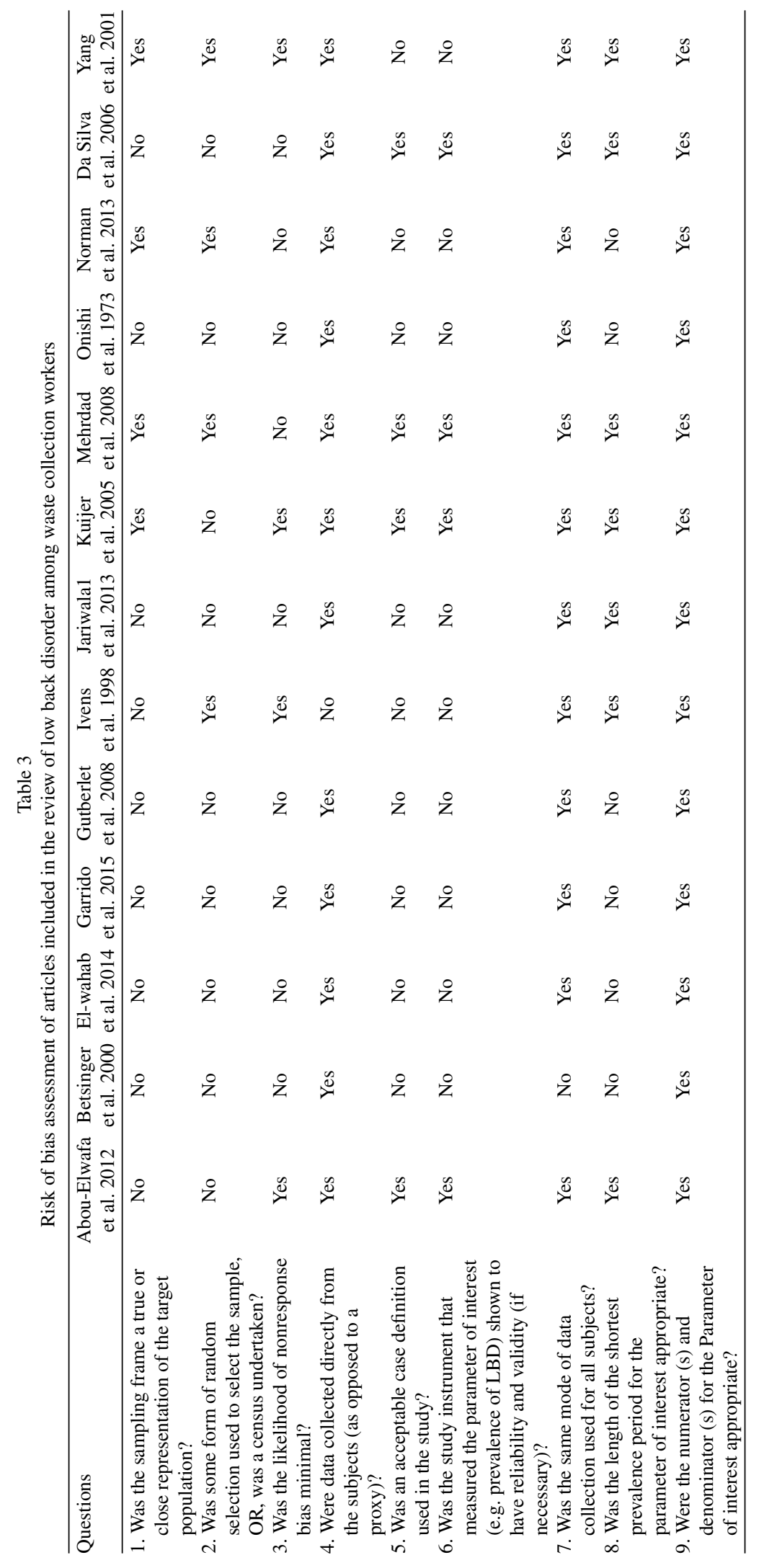


work duration [13, 30, 35] smoking [30], physical work load [7, 35], vibration [35] and awkward posture during work [13, 23, 35] were the risk factors suggested in the reviewed articles. However, none of these studies specifically investigated the association between risk factors and LBD. Therefore, there is need for future studies to explore the association between these risk factors and low back disorders in this potentially high-risk occupational group.

\subsection{Generalizability of results}

Although waste management likely occurs in most areas of the world, not all geographical regions are represented in the articles included in this review. The 13 included studies reported on 11 different countries, which are likely to vary considerably in degree of informality/formality, labour regulations, overall working conditions and even waste types. The health and safety regulatory framework within a region are likely to impact the general awareness and tolerance for poor working conditions, and the recourse available to workers when conditions are deemed unacceptable. Furthermore, eight of the thirteen studies were conducted in low-income (i.e. 'developing') countries where waste management is primarily manual, compared to high-income nations where there is an increase in mechanized approaches for managing waste. However, the use of mechanical methods of managing waste does not guarantee the safety of waste workers, since workers often stand for long hours and undertake repetitive movements whilst trying to control machinery [44]. As waste collection in a global context is predominantly manual [15], there is a need for further studies in other developing regions to fully understand the impact of LBD in waste workers worldwide. Certain groups such as women may not have been proportionately represented. For example, 7 articles included both men and women participants; however, in all 7 articles men represented a higher proportion (2227/3117, $71 \%$ men). Additionally, 5 out of the 13 articles included only male participants. There are proportionately more men in the waste industry, as seen in the Canadian waste management workforce where men represent $77 \%$ of the solid waste management workforce [45]. Still, there is the need to consider the geographical and social context in which these 13 articles were conducted to better understand the results.

The quality of the included articles were appraised based on an assessment scale proposed by Hoy et al. [22]. Overall, the included articles showed moder- ate weakness in methodological quality assessment, in that most of the articles did not report using random sampling methods or clearly demonstrate that non-response bias was minimized. Randomization prevents selection bias to a large extent, so not doing it might affect the reliability and validity of the study results by introducing bias which would have ultimately over or under estimated the study findings [46]. Future studies should improve their sampling strategies to mitigate bias and improve study quality.

\subsection{Strengths and limitations}

This systematic review is among the first to summarize the prevalence and risk factors of LBD among waste workers, and provides a summary of prevalence of LBD among waste workers. The search for these 13 articles was undertaken systematically in 3 electronic scientific databases using an extensive comprehensive list of search terms as shown in the supplemental material. The dual reviewers and consistency in screening and extraction enhanced the reliability of the findings. In addition, risk of bias was assessed using a standardized tool developed specifically for LBD prevalence studies [22]. However, there are also limitations to this systematic review. Only three databases were used due to time and resource limitations; however, consultation with a research librarian regarding the most appropriate databases mitigated this limitation. Relevant articles from specific regions, which are not in English language, could have been missed. Also, this review could have missed articles in smaller journals, which are likely to be not indexed in the databases used. Two articles were excluded from the review because full-text was not available, and it is possible inclusion of these articles might have enriched the review data.

\subsection{Conclusion}

The generation of waste, if not appropriately collected and/or managed, poses a health risk to humans and the environment, so waste management is necessary work. This systematic review used descriptive analysis to summarize the prevalence of LBD among waste workers in 13 included articles, and found 12month prevalence rates ranging from 16 to $74 \%$. None of the included studies met all 9 risk of bias criteria, and so cannot be considered high-quality. The review aimed to also identify risk factors for LBD in this workforce, but our systematic search did not yield any articles that quantified relation- 
ships between LBD and risk factors, identifying a gap in the literature in this high-risk occupational group. Although many authors theorized as to the causes of LBD in this workforce, none of the studies provided quantitative evidence of the association of suggested risk factors such as lifting or twisting. It would be valuable to assess these risk factors through direct measurement to get a realistic and accurate picture of the nature of this type of work. Therefore, there remains a need for future studies to quantify the risk factors for LBD among waste workers in order to assist in developing interventions and preventive measures. An enhanced understanding of exposure-response relationships would contribute to development of interventions and preventative measures at the workplace to prevent LBD.

\section{Acknowledgment}

Appreciation goes to Dr. Catherine Boden of the Irene and Leslie Dubé Health Sciences Library for her advisement and support with the literature search.

\section{Conflict of interest}

None to report.

\section{Supplementary material}

The supplementary material is available in the electronic version of this article: http://dx.doi.org/ 10.3233/wor-192977.

\section{References}

[1] Rubin DI. Epidemiology and risk factors for spine pain. Neurol Clin. 2007;25(2):353-71.

[2] Waddell G. Diagnostic Triage. In: The Back Pain Revolution. Second. Toronto: Churchill Livingstone; 2004. pp. 9-26.

[3] Hoy D, Brooks P, Blyth F, Buchbinder R. The Epidemiology of low back pain. Best Pract Res Clin Rheumatol. 2010;24(6):769-81.

[4] Woolf AD, Pfleger B. Burden of major muskuloskeletal conditions. Bull World Heal Organ. 2003;81(03):646-56.

[5] Hoy D, March L, Brooks P, Blyth F, Woolf A, Bain C, et al. The global burden of low back pain: Estimates from the Global Burden of Disease 2010 study. Ann Rheum Dis. 2014;73(6):968-74

[6] Vos T, Flaxman AD, Naghavi M, Lozano R, Michaud C, Ezzati M, et al. Years lived with disability (YLDs) for 1160 sequelae of 289 diseases and injuries 1990-2010: A systematic analysis for the Global Burden of Disease Study 2010. Lancet. 2012;380(9859):2163-96.

[7] Porta D, Milani S, Lazzarino AI, Perucci C, Forastiere F. Systematic review of epidemiological studies on health effects associated with management of solid waste. Environ Health. 2009;8:60.

[8] Thayyil Jayakrishnan, Mc Jeeja RB. Occupational health problems of municipal solid waste management workers in India. Int $\mathbf{J}$ Environ Health Eng [Internet]. 2013;2(1):42. Available from: http://www.ijehe.org/article. asp?issn $=2277-9183$; year $=2013$; volume $=2$; issue $=1$; spage $=$ 42; epage $=42$; aulast $=$ Jayakrishnan

[9] Rushton L. Health hazards and waste management. British Medical Bulletin. 2003;68:183-97.

[10] Mehrdad R, Majlessi-Nasr M, Aminian O, Sharufian SA, Malekahmadi F. Musculoskeletal disorders among municipal solid waste workers. Acta Med Iran [Internet]. 2008;46(3):1-6. Available from: http://journals.tums. ac.ir/abs/8836

[11] Thirarattanasunthon P, Siriwong W, Robson M, Borjan M. Health risk reduction behaviors model for scavengers exposed to solid waste in municipal dump sites in Nakhon Ratchasima Province, Thailand. Risk Manag Healthc Policy. 2012;5:97-104.

[12] Gutberlet J, Baeder AM. Informal recycling and occupational health in Santo André, Brazil. Int J Environ Health Res [Internet]. 2008;18(1):1-15. Available from: http://www.ncbi.nlm.nih.gov/pubmed/18231943

[13] Velasco Garrido M, Bittner C, Harth V, Preisser AM. Health status and health-related quality of life of municipal waste collection workers - A cross-sectional survey. J Occup Med Toxicol. 2015;10(1):22.

[14] Da Silva MC, Fassa AG, Kriebel D. Musculoskeletal pain in ragpickers in a southern city in Brazil. Am J Ind Med. 2006;49(5):327-36.

[15] Abou-ElWafa HS, El-Bestar SF, El-Gilany A-H, Awad EES. Musculoskeletal disorders among municipal solid waste collectors in Mansoura, Egypt: A cross-sectional study. Bristish Med J Open. 2012;2(5):1-8.

[16] International Labour Organization International Standard Classification of Occupations.

[17] Dias ÂRO e S. Waste pickers in Belo Horizonte, Brasil: Statistics, contributions and challenges (Catadoras e Catadores em Belo Horizonte) [Internet]. Belo Horizonte, Brazil; 2013. Available from: http://www.wiego.org/sites/ wiego.org/files/publications/files/IEMS-Belo-Horizonte-Wa ste-Pickers-City-Report-Portuguese.pdf

[18] Hoornweg D, Bhada-Tata P. What a Waste: A Global Review of Solid Waste Management. Fed Eur Biochem Soc [Internet]. 2014;281(19):4556. Available from: http://www. ncbi.nlm.nih.gov/pubmed/25270340

[19] Agbesola Y. Sustainability of Municipal Solid Waste Management (Masters Thesis) [Internet]. Linköping University; 2013. Available from: http://www.nswaienvis.nic.in/Waste Portal/Case_Studies_30.10.14/Sustainability-of-MunicipalSolid-Waste-Management-in-Nigeria.PDF

[20] Cointreau S. Occupational and environmental health issues of solid waste management: Special emphasis on middle and lower-income countries. World Bank, Washington, DC [Internet]. 2006;1-47. Available from: http://www.ircwash. org/resources/occupational-and-environmental-health-issu es-solid-waste-management-special-emphasis

[21] Trask C, Khan MI, Adebayo O, Boden C, Bath B. Equity in Whom Gets Studied: A Systematic Review Examining 
Geographical Region, Gender, Commodity, and Employment Context in Research of Low Back Disorders in Farmers. J Agromedicine. 2015;20(3).

[22] Hoy D, Brooks P, Woolf A, Blyth F, March L, Bain C, et al. Assessing risk of bias in prevalence studies: Modification of an existing tool and evidence of interrater agreement. J Clin Epidemiol. 2012;65(9):934-9.

[23] Betsinger G, Brosseau LM, Golden J. Occupational Health and Safety in Household Hazardous Waste Management Facilities. AIHAJ - Am Ind Hyg Assoc. 2000;61(4): 575-83.

[24] Ivens UI, Lassen JH, Kaltoft BS, Skov T. Injuries among domestic waste collectors. Am J Ind Med. 1998;33(2):1829.

[25] Kuijer P, Frings-Dresen M, De Looze M, Visser B, Van Der Beek A. Work situation and physical workload of refuse collectors in three different time periods. Int J Ind Ergon. 2000;26(5):509-19.

[26] Onishi N, Hideko N. Low Back Pain in Relation To Physical Work Capacity and Local Tenderness. J Hum Ergol. 1973;2:119-32.

[27] Abd El-Wahab E, Eassa S, Lotfi S, Masry S, Shatat H, Kotkat A. Adverse health problems among municipality workers in Alenxandria, Egypt. Int J Prev Med. 2014;5(5):545-56.

[28] Jariwala ND, Christian RA. A study of prevalance of morbities in door to door waste collecting workers of Surat City, Gujarat. Indian J Public Heal Res Dev. 2013;4(4):123-7.

[29] Norman ID, Kretchy JP, Brandford E. Neck, Wrist and Back Pain Among Solid Waste Collectors: Case Study of a Ghanaian Waste Management Company. Open Public Heal Journal,. 2013;6:59-66.

[30] Yang C-Y, Chang W-T, Chuang H-Y, Tsai S-S, Wu T-N, Fung-Chang S. Adverse health effects among household waste collectors in Taiwan. Environ Res. 2001;85(3):195-9.

[31] Kuijer PPF, Verbeek JH, Visser B, Elders LA, Van Roden N, Van den Wittenboer ME, et al. An EvidenceBased Multidisciplinary Practice Guideline to Reduce the Workload due to Lifting for Preventing Work-Related Low Back Pain. Ann Occup Environ Med [Internet]. 2014;26(1):16. Available from: http://europepmc.org/ articles/PMC4081511/?report=abstract

[32] Hoy D, Bain C, Williams G, March L, Brooks P, Blyth F, et al. A systematic review of the global prevalence of low back pain. Arthritis Rheum. 2012;64(6):2028-37.

[33] Deyo RA, Dworkin SF, Amtmann D, Andersson G, Borenstein D, Carragee E, et al. Report of the NIH Task Force on Research Standards for Chronic Low Back Pain. J Pain. 2014;15(6):569-85.
[34] Dionne CE, Dunn KM, Croft PR, Nachemson AL, Buchbinder R, Walker BF, et al. A Consensus Approach Toward the Standardization of Back Pain Definitions for Use in Prevalence Studies. Spine (Phila Pa 1976). 2008;33(1):95103.

[35] Kuijer PPFM, Van Der Beek AJ, Van Dieën JH, Visser B, Frings-Dresen MHW. Effect of job rotation on need for recovery, musculoskeletal complaints, and sick leave due to musculoskeletal complaints: A prospective study among refuse collectors. Am J Ind Med. 2005;47(5):394-402.

[36] Paudyal P, Ayres JG, Semple S, Macfarlane GJ. Low back pain among textile workers: A cross-sectional study. Occup Med (Chic Ill). 2013;63(2):129-34.

[37] Dajah S Al, Daghdi A Al. Prevalence and Risk Factors of Low Back Pain among Nurses in Sudayr Region. Int J Occup Hyg [Internet]. 2015;7(1):45-52. Available from: http://ijoh.tums.ac.ir/index.php/ijoh/article/view/129

[38] Omokhodion FO, Umar US, Ogunnowo BE. Prevalence of low back pain among staff in a rural hospital in Nigeria. Occup Med (Lond). 2000;50(2):107-10.

[39] Ghaffari M, Alipour A, Jensen I, Farshad AA, Vingard E. Low back pain among Iranian industrial workers. Occup Med (Chic Ill). 2006;56(7):455-60.

[40] Free MM. Cross-cultural conceptions of pain and pain control. Proc (Bayl Univ Med Cent). 2002;15(2):143-5.

[41] Mossey JM. Defining racial and ethnic disparities in pain management. Clin Orthop Relat Res. 2011;469(7):1859-70.

[42] Malchaire J, Cock N, Vergracht S. Review of the factors associated with musculoskeletal problems in epidemiological studies. Int Arch Occup Environ Health. 2001;74(2):79-90.

[43] Bath B, Trask C, McCrosky J, Lawson J. A biopsychosocial profile of adult Canadians with and without chronic back disorders: A population-based analysis of the 20092010 Canadian Community Health Surveys. Biomed Res Int. 2014;2014:919621.

[44] Norman R, Wells R. Ergonomic Interventions for Reducing Musculoskeletal Disorders: An Overview, Related Issues and Future Directions [Internet]. Waterloo; 1998. Available from: http://www.qp.gov.bc.ca/rcwc/research/normanwells-interventions.pdf

[45] of Canada ECO. SOLID WASTE MANAGEMENT [Internet]. Vol. 3. 2010. Available from: http://www.eco.ca/ ecoreports/pdf/Solid-Waste-Management-Labour-MarketResearch-2010.pdf

[46] Higgins JP, Altman DG. Assessing Risk of Bias in Included Studies. In: Cochrane Handbook for Systematic Reviews of Interventions: Cochrane Book Series. 2008. pp. 187-241. 